NBER WORKING PAPER SERIES

\title{
INFORMATION, AVOIDANCE BEHAVIOR, AND HEALTH: THE EFFECT OF OZONE ON ASTHMA HOSPITALIZATIONS
}

\author{
Matthew J. Neidell \\ Working Paper 14209 \\ http://www.nber.org/papers/w14209
NATIONAL BUREAU OF ECONOMIC RESEARCH
1050 Massachusetts Avenue
Cambridge, MA 02138
July 2008

I thank Janet Currie, Michael Greenstone, Ken Chay, Sherry Glied, Enrico Moretti, Helen Levy, Will Manning, Tomas Philipson, Sylvia Brandt, Elizabeth Powers, Michael Khoo, Joshua Graff Zivin, Amanda Lang, Paul Rathouz, Bob Kaestner, Kerry Smith, Pat Bayer, Wes Hartmann, an anonymous referee, and numerous seminar participants for valuable feedback. I am also very grateful to Bruce Selik and Joe Cassmassi of the South Coast Air Quality Management District for providing information on smog alerts, Mei Kwan, E.C. Krupp, and Ken Warren for help with obtaining the attendance data used for this analysis, and Sarah Kishinevsky, Mike Kraft, and Sonalini Singh for excellent research assistance. Financial support from the University of Chicago's Center for Integrating Statistical and Environmental Science is gratefully acknowledged. The views expressed herein are those of the author(s) and do not necessarily reflect the views of the National Bureau of Economic Research.

NBER working papers are circulated for discussion and comment purposes. They have not been peerreviewed or been subject to the review by the NBER Board of Directors that accompanies official NBER publications.

(C) 2008 by Matthew J. Neidell. All rights reserved. Short sections of text, not to exceed two paragraphs, may be quoted without explicit permission provided that full credit, including $\odot$ notice, is given to the source. 
Information, Avoidance Behavior, and Health: The Effect of Ozone on Asthma Hospitalizations Matthew J. Neidell

NBER Working Paper No. 14209

July 2008

JEL No. D80,I12,I18,Q53

\begin{abstract}
$\underline{\text { ABSTRACT }}$
This paper assesses whether responses to information about risk impact estimates of the relationship between ozone and asthma in Southern California. Using a regression discontinuity design, I find smog alerts significantly reduces daily attendance at two major outdoor facilities. Using daily time-series regression models that include year-month and small area fixed effects, I find estimates of the effect of ozone for children and the elderly that include information are significantly larger than estimates that do not. These results are consistent with the hypothesis that individuals take substantial action to reduce exposure to risk; estimates ignoring these actions are severely biased.
\end{abstract}

Matthew J. Neidell

Department of Health Policy and Management

Columbia University

600 W 168th Street, 6th Floor

New York, NY 10032

and NBER

mn2191@columbia.edu 


\section{Introduction}

Information about risk is provided in numerous areas of public health so individuals can adjust their behavior when confronted with risk. Observational analyses that estimate health effects from exposure to these risks, however, typically assume no behavioral responses to risk. For example, several recent studies examining the effect of outdoor air pollution on health provide convincing empirical evidence of exogenous variation in ambient pollution, but do not account for actions individuals may take to reduce their exposure to pollution, such as decreasing the amount of time spent outside (for example, Friedman et al. 2001; Chay and Greenstone 2003a,b; Currie and Neidell 2005). Even if ambient pollution levels are as good as randomly assigned, exposure to pollution remains endogenous, so estimates of the biological effect of pollution on health are biased.

This paper assesses whether behavioral responses to information about risk impact estimates of the relationship between ozone and asthma hospitalizations in Southern California. Avoidance behavior is especially pervasive in this context because information about pollution is so widespread. The Los Angeles Times, the most widely circulated newspaper in the region, provides the pollutant standards index (PSI), ${ }^{2}$ a continuous index that converts forecasted daily pollution levels into an easily understandable format and, depending on the level of pollution, advises the public regarding health effects and precautionary actions to take (Environmental Protection Agency 1999). Furthermore, various media channels, including television and radio, announce “smog alerts” when forecasted ambient ozone exceeds a particular threshold. These alerts encourage susceptible individuals, such as children and the elderly, to avoid exposure to ozone by remaining indoors and all others to avoid rigorous outdoor activity. Importantly, both

\footnotetext{
2 The Air Quality Index replaced the PSI in 1999, but data in this analysis goes through 1997.
} 
sources of information are forecasted a day in advance to provide ample time for individuals to react.

To assess the impact of responses to information about risk, this paper proceeds in two stages. First, I estimate whether people respond to information about pollution by examining the effect of smog alerts on daily outdoor activities. As a measure of outdoor activities, I use daily attendance from 1989 to 1997 at two major outdoor facilities in Southern California: the Los Angeles Zoo and Griffith Park Observatory. To identify the effect of smog alerts, I employ a regression discontinuity design by exploiting the deterministic selection rule used for issuing alerts. If days just above or below the smog alert threshold do not vary systematically with outdoor activity decisions, then I can obtain estimates of the causal effect of alerts on avoidance behavior. In support of this approach, other observable characteristics, such as weather and observed pollution, move smoothly around this threshold, suggesting any change in outdoor activities at this threshold can be directly attributed to smog alerts.

The second stage of this paper focuses on estimating the bias from incorporating these responses by examining the impact of ozone on asthma hospitalizations. If individuals respond to information about ozone and ozone affects health, then accounting for responses should increase the estimated effect of ozone. To identify the effect of ozone, I estimate daily timeseries regression models that include year-month fixed effects and finely defined geographic area fixed effects. The year-month fixed effects non-parametrically absorb seasonal and temporal trends in ozone and health. The area fixed effects capture observed and unobserved factors common to residents within that area, such as income, education, and access to health insurance, to the extent they do not vary over time. I also include extensive controls for weather, other outdoor pollutants, and day of week dummy variables to capture time varying factors. The 
remaining variation in ozone is likely independent from the numerous behavioral and environmental factors that affect health.

The first set of results indicates that people respond to smog alerts. Attendance is significantly lower on days when smog alerts are announced, with declines in preferred specifications of 6 and 13 percent across the two facilities considered. These results are generally insensitive to functional form assumptions of the regression discontinuity design and are robust to several specification checks. For example, the estimates are remarkably unaffected by the inclusion of numerous controls for weather conditions and observed air quality, both significant predictors of outdoor activities. Attendance for children and the elderly, two groups specifically targeted by air quality information, display greater responses to alerts. These findings indicate that people value the provision of information contained in the warnings.

The second set of results confirms that accounting for responses to information about risk drastically alters conclusions about the relationship between ozone and health, though only for susceptible populations. Ignoring avoidance behavior suggests ozone has the smallest effect on children, while controlling for avoidance behavior indicates the biggest effect on children. Including smog alerts and the PSI increases estimates of the effect of ozone by roughly 160 percent for children and 40 percent for the elderly, but has no effect on estimates for adults. These patterns by age are consistent with children and the elderly having greater response to alerts than adults.

The coefficients on information about risk can also be directly interpreted for understanding the effect of ozone on health. If providing information improves health ceteris paribus - importantly, holding observed ozone levels fixed - this implies evidence of both a response to information and an effect of ozone on health. For example, if individuals respond to 
an alert by reducing their exposure to ozone and, consequently, their health improves, then ozone must affect health. I find that information has a significant, negative effect on hospitalizations for children and the elderly, further supporting that ozone effects health.

Evidence that people respond to public information about risk is interesting in own right. First, studies consistently document that individuals adjust their behavior in response to information about permanent, long-standing risk. ${ }^{3}$ Information is often disseminated to shape individuals' short-run behavior in response to imminent dangers, such as terrorism threats, environmental hazards, and disease outbreaks, and these findings indicate that people respond to rapidly changing information about risk. Second, economic epidemiology models imply that diseases can be self-limiting through avoidance behavior, so there may be little role for government intervention (Philipson 2000). Studies that examine behavioral responses to disease outbreaks, however, are unable to distinguish how information about risk is transmitted as a disease spreads, whether by private or public information. ${ }^{4}$ Because air quality information is publicly provided, these findings indicate the government has a potential role in affecting illness by disseminating information about risk.

Most importantly, these results are consistent with the hypothesis that individuals take substantial actions to reduce exposure to ozone; estimates of the health effect of ozone that ignore these actions are severely biased. Given the contentious debates surrounding air quality regulations, ${ }^{5}$ it is important to account for this behavior to correctly measure the costs of ozone to society. Moreover, given the widespread prevalence of information about risk, these findings suggest the importance of accounting for protective behavior in a wide range of statistical analyses that rely on observational data to understand biological relationships.

\footnotetext{
${ }^{3}$ For example, see Ippolito and Mathios (1990), Jin and Leslie (2003), and Smith and Johnson (1988).

${ }^{4}$ For example, see Ahituv, Hotz, and Philipson (1996), Mullahy (1999), and Philipson (1996).
} 


\section{Background}

\section{A. Air Quality and Health}

One of the most influential studies on air pollution and health comes from the London “killer” fog, a severe air pollution episode in London, England, in December, 1952 (Wilson and Spengler 1996). The unexpected - and arguably exogenous - change in air quality stemming from a temperature inversion has been linked with thousands of premature deaths (Logan and Glasg 1953). Since air quality was not regularly monitored and its health effects were poorly understood (and fog was common in London), people were largely uninformed of the harm they faced from exposure, so there was limited, if any, avoidance behavior.

More recent studies have focused on determining effects from air pollution at the lower levels commonly found in developed countries. Countless observational analyses have estimated statistical associations between pollution and various health outcomes, mostly focusing on mortality and respiratory related morbidity, such as asthma, with summaries provided in Levy et al. (2001), Brunekreef and Holgate (2002), Wilson and Spengler (1996), and Environmental Protection Agency (2006). A common statistical approach is the use of daily time-series data on health outcomes, such as hospitalizations, linked with contemporaneous and lagged levels of pollution and potential confounding variables, such as weather (for example, Katsouyanni et al. 1996, Thurston et al. 1992, Schwartz 1995, Bell et al. 2004). An alternative approach is cohort studies that follow individuals over time and compare pollution measures aggregated over time with health outcomes (for example, Dockery et al. 1993, Pope et al. 1995, Kinney, Thurston, and Raizenne 1996).

These approaches have been criticized on the grounds that ambient pollution is not randomly assigned (Chay and Greenstone 2003a,b), leading to a surge in quasi-experimental

\footnotetext{
${ }^{5}$ For example, new air quality standards for ozone were proposed in 1997 and upheld in court until 2003.
} 
techniques to isolate exogenous changes in pollution. For example, several studies by Pope and others (Pope 1989, Pope, Schwartz, and Ransom 1992, Ransom and Pope 1995) used changes in pollution that resulted from the opening and closing of a steel mill in Utah because of a labor strike. Heinrich, Hoelscher, and Wichmann (2000) exploited changes in total suspended particles (TSPs) in Eastern Germany from shifts in industrial activity and stricter air quality regulations as a result of German reunification in 1990. Friedman et al. (2001) used the temporary change in air quality from short-term traffic rules intended to accommodate the 1996 Olympic Games in Atlanta, GA. Two studies by Chay and Greenstone (2003a,b) exploited the implementation of the Clean Air Act of 1970 and the recession of the early 1980s that induced considerable temporal and spatial variation in TSPs throughout the United States. Lederman et al. (2004) compared birth outcomes of children born to women living or working within two miles of the World Trade Center who were pregnant on September 11, 2001, to children born to women more than two miles away. Lleras-Muney (2005) used the plausibly random relocation of military personnel to new residential locations to estimate the effect of various pollutants on children's health. ${ }^{6}$

Although these studies often go to great lengths to provide convincing empirical evidence that ambient pollution levels can be viewed as randomly assigned, they typically assume people do not respond to their assigned level of pollution. Unlike the early killer fog episodes where people were largely unaware of the danger associated with pollution levels, the scope for avoidance behavior has increased considerably over time, though the extent to which it exists may vary depending on the specific context. If people respond to higher pollution levels by increasing avoidance behavior, then the estimated effect of pollution on health is biased down.

\footnotetext{
${ }^{6}$ For examples of other studies, see Currie and Neidell (2005), Neidell (2004), Jayachandran (2005), and Sneeringer (2006).
} 


\section{B. Ozone, Asthma, and Information}

Ground-level ozone is a criteria pollutant ${ }^{7}$ regulated under the Clean Air Acts that affects respiratory morbidity by irritating lung airways, decreasing lung function, and increasing respiratory symptoms, with effects exacerbated for susceptible individuals, such as children, the elderly, and particularly asthmatics. Because it takes some time for a disease such as asthma to progress, symptoms can arise from contemporaneous exposure (in as quickly as one hour of exposure), from cumulative exposure over several days, or several days after exposure. For example, "an asthmatic may be impacted by ozone on the first day of exposure, have further effects triggered on the second day, and then report to the emergency room for an asthmatic attack three days after exposure” (Environmental Protection Agency 2006).

Numerous studies have documented associations between ozone and hospital admissions for asthma using daily time series data - the approach taken in this paper - with the most comprehensive review provided in Environmental Protection Agency (2006). Evidence generally supports significant increases in asthma hospitalizations as ozone increases, though it is not uncommon to find no association (for example, Norris et al. 1999, Lierl and Hornung 2003, Garty et al. 1998). Cumulative effects are supported by the data, with the largest effect on hospital admissions from one lag of ozone, followed by two lags, then zero, three, and four lags in a virtual tie, with no effect established beyond four lags (Environmental Protection Agency 2006).

The process leading to ozone formation makes it highly predictable and straightforward to avoid. Ozone is not directly emitted into the atmosphere, but is formed from interactions of nitrogen oxides (NOx) and volatile organic compounds (VOCs) (both of which are directly

\footnotetext{
${ }^{7}$ Criteria pollutants are six common air pollutants with established health-based air quality standards. They include ozone, carbon monoxide, particulate matter, nitrogen dioxide, lead, and sulfur dioxide.
} 
emitted) in the presence of heat, sunlight, and solar radiation. Because of this process, ozone levels vary considerably both across and within days, peaking in the summer and middle of the day when heat, sunlight, and solar radiation are highest (Environmental Protection Agency 2006). Therefore, ozone levels can be predicted using weather forecasts, and ozone rapidly breaks down indoors because there is less heat and sunlight (Chang et al. 2000). Since symptoms from ozone exposure can arise over a short period of time, altering short-run exposure by going indoors can reduce the onset of symptoms.

Because of the potential effectiveness of avoidance behavior, the pollutant standards index (PSI) was developed to inform the public of expected air quality conditions. The PSI, which is forecasted on a daily basis, ranges from $0-500$ and is indexed so that a value of 100 corresponds to the National Ambient Air Quality Standards set forth in the Clean Air Acts. The PSI is computed for five of the criteria pollutants, and the maximum PSI across pollutants is required by federal law to be reported in major newspapers (Environmental Protection Agency 1999). It also contains a brief legend summarizing the air quality: 0-50 good; 51-100 moderate; 101-200 unhealthful; 201-275 very unhealthful; and 275+ hazardous.

In addition to providing the PSI, California state law requires the announcement of a stage I air quality episode when the PSI is at least 200, which corresponds to 0.20 parts per million (ppm) for ozone. ${ }^{8}$ These episodes, which also occur on a daily basis, are more widely publicized than the PSI; they are announced on both television and radio. Although air quality episodes can potentially be issued for any criteria pollutant, they have only been issued for ozone. Compatible with seasonal patterns of ozone, alerts are issued from March 1 to October 31. Because ozone is a major component of urban smog, this has given rise to the term "smog

\footnotetext{
${ }^{8}$ Additionally, a stage II air quality episode is issued when the PSI exceeds 250 or ozone forecast exceeds $0.30 \mathrm{ppm}$, but this only occurred once over the time period studied.
} 
alerts.”

The agency that provides air quality forecasts and issues smog alerts for Southern California is the South Coast Air Quality Management District (SCAQMD). They produce the following day’s air quality forecast by noon the day before to provide enough time to disseminate the information. Because SCAQMD covers all of Orange County and the most populated parts of Los Angeles, Riverside, and San Bernardino counties - an area with considerable spatial variation in ozone - they provide the forecast for each of the 38 source receptor areas (SRAs) within SCAQMD. When an alert is issued, the staff at SCAQMD contacts a set list of recipients, including local schools and newspapers. The media then further circulate the information to the public, but greatly condense it. For example, the Los Angeles Times, although it receives air quality forecasts for all 38 SRAs in SCAQMD, only reports air quality forecasts for ten air monitoring areas (AMAs) in SCAQMD by taking the maximum forecasted value of the SRAs within an AMA.

Given the reporting process and the factors believed to affect ozone formation, the model used for issuing an alert can be summarized as:

$$
\text { alert }_{\text {at }}=1\left\{\max _{\text {at }}\left(\text { ozone }_{s t}^{f}=f\left(\text { weather }_{\text {st }}^{f} \text { ozone } \text { st }-1_{1}, \text { solrad }_{t}\right)\right) \geq 0.20\right\}
$$

where the subscripts $a$, $s$ and $t$ indicate AMA, SRA, and date, respectively, ozone $e^{f}$ is the forecasted 1-hour level of ozone, weather ${ }^{f}$ is the weather forecast, ozone is observed 1-hour ozone, solrad is solar radiation, and $1\{\bullet\}$ is an indicator function equal to one when the forecasted ozone exceeds $0.20 \mathrm{ppm}$ and 0 otherwise.

\section{Data}

\section{$\underline{\text { A. Outdoor attendance }}$}

For a measure of time spent outdoors, accurately recorded individual level time diaries 
would be an ideal source of data, but such data are generally unavailable at a daily level over a sufficient period of time. I instead use daily aggregate measures of attendance at two outdoor facilities within the boundaries of the SCAQMD: the Los Angeles Zoo and Botanical Gardens (“Zoo”) and Griffith Park Observatory (“Observatory”). ${ }^{9}$ The Zoo is open everyday from 10 a.m. to 5 p.m., with the closing time extended to 6 p.m. from July 1 to Labor Day. The Observatory is open from 2 p.m. to 10 p.m. Tuesday through Friday and 12:30 p.m. to 10 p.m. on Saturday and Sunday, but is open from 12:30 p.m. to 10 p.m. everyday during the summer. Both are located a short distance from downtown Los Angeles and attract sizeable crowds, averaging over 4500 attendees per day. These data are available from 1989-1997, with descriptive statistics for each shown in Table 1.

Although focusing on two specific facilities limits generalizability, these data provide several advantages over time use surveys. One, because they are administrative data, they are likely to be free of recall errors that often arise in survey data. Two, these data are available over a long period of time in which there is substantial variation in ozone levels, forecasts, and smog alerts. Three, the exact dates are available in the attendance data, allowing me to merge several files at the daily levels and use the regression discontinuity design. Therefore, this approach improves upon measurement, precision, and causality at the expense of generalizability.

The Zoo charges varying admission fees, so it also offers some breakdown of attendance by demographics to assess heterogeneity in responses to alerts. Separate daily attendance is available for adults, children under 2, children aged 2-12, and seniors aged 62 and up, with means for each presented in Table 1. Children and the elderly are two groups considered susceptible to the effects of ozone, so their responses may differ from adults. ${ }^{10}$ Although this

\footnotetext{
${ }^{9}$ The Zoo and Observatory are owned and operated by the City of Los Angeles.

${ }^{10}$ Children's responses to alerts could reflect state rules requiring schools to reschedule outdoor activities, but the
} 
definition of susceptibility is not exhaustive, both groups are specifically targeted by air quality information. The Zoo also offers attendance for Greater Los Angeles Zoo Association (GLAZA) members. While the Zoo is both a tourist and local attraction, GLAZA members are typically local residents who may be more aware of alerts and find it easier to switch activities. ${ }^{11}$ Therefore, they are more likely to respond to alerts, providing one robustness check of the model.

I also collect data on attendance at baseball games (available in the 'game logs' at www.retrosheet.org) for two major league baseball teams in SCAQMD: the Los Angeles Dodgers, who play a short distance form downtown Los Angeles, and the California Angels ${ }^{12}$, who play in Anaheim, approximately 30 miles southeast of downtown Los Angeles. Attending a baseball game is a more sedentary activity than attending the Zoo or Observatory and most baseball games are played at night when ozone levels decrease, so I use attendance at games as a specification check. Average attendance from 1989-1997, which includes advance ticket sales and purchases the day of the game, is over 37,000 for the Dodgers and 26,000 for the Angels. The sample size for both teams is considerably smaller than the Zoo and Observatory because the baseball season is shorter than the smog alert season and because games are not played every day in Southern California.

\section{B. Health Outcomes}

Data on health outcomes comes from a non-public version of the California Hospital Discharge Data (CHDD), which contains records for all individuals discharged from a hospital in the state. The non-public version contains the exact date of admission and the patients'

analysis focuses almost exclusively on summer months when children are not in school and also includes a dummy variable for summer schedule.

${ }^{11}$ GLAZA members pay an annual fee and do not pay an admission fee per visit. 
residential ZIP code, which are used to assign individuals to information, pollution, and weather. The principal diagnosis of the patient is used to identify asthma admissions based on the International Classification of Diseases, 9th Revision, Clinical Modification (ICD-9-CM) codes. Since the effects of pollution and responses to information may vary by age, I use the age of the patient to separate admissions by age. Although an imperfect measure of health, asthma hospital admissions from the CHDD provide a large sample of data at a high frequency with detailed geographic residence.

For the dependent variable, I compute the daily number of hospital admissions for asthma in each SRA, also shown in Table 1. I compute asthma admissions for three age groups: 5-19, 20-64, and 65 and over. ${ }^{13}$ The value of 0.369 for ages 5-19 in the first column indicates there are 0.369 hospital admissions per day for asthma per SRA, which translates into nine admits per day for all of SCAQMD, shown in the second column.

\section{Air quality information}

I collected forecasted ozone directly from the Los Angeles Times for the years 1989-1997. Since the Times only reports air quality forecasts for each AMA (although it receives forecasts for each SRA), the AMA is the finest geographic resolution for pollution information. For data on smog alerts, I obtained an administrative file from SCAQMD that contained dates when alerts were issued anywhere in the district but not the area it was issued for. Because there is considerable spatial variation in ozone levels throughout SCAQMD, I instead assign an alert to each AMA if the ozone forecast in that AMA (from the Times) equals or exceeds $0.20 \mathrm{ppm}$, according to equation (1). ${ }^{14}$ To verify the appropriateness of assigning alerts, I created an

\footnotetext{
${ }^{12}$ The California Angels were renamed the Anaheim Angels in 1997, and then the Los Angeles Angels of Anaheim in 2005.

13 I omit children less than five because of difficulties in correctly diagnosing asthma at this age.

14 The ozone forecast is reported in PSI units, rather than ppm that observed ozone levels are recorded. Because the
} 
indicator for whether an alert was issued anywhere in SCAQMD and compare it to the SCAQMD administrative file. The selection rule in equation (1) is strictly followed: there are only seven inconsistencies of the 2138 data points available over the period studied.

Since alerts are forecasted, I assess their accuracy by using data on observed ozone for each AMA, also shown in Table 1. Of the 104 alerts issued in the AMA for the Zoo, less than 20 percent were correctly issued; conversely, there were 35 days where ozone surpassed $0.20 \mathrm{ppm}$ but no alert was issued. Accuracy for the rest of SCAQMD is comparable to the AMA of the Zoo. If people track alert accuracy, the inaccuracy of alerts may be problematic for encouraging people to respond. ${ }^{15}$ It is, however, useful for the regression discontinuity design: if scientists and meteorologists cannot distinguish between days above and below the threshold, then it is unlikely that individuals can.

\section{Pollution and weather}

Daily pollution data is from the California Air Resources Board. There is approximately one pollution monitor for ozone in each of the 38 SRAs, and roughly 20 for carbon monoxide (CO) and nitrogen dioxide $\left(\mathrm{NO}_{2}\right)$, two other pollutants necessary to control for because of their correlation with ozone and potential health effects. ${ }^{16}$ I assign pollution levels to the SRA based on the values for the monitor in that SRA and drop SRAs if no monitor is present for ozone. If an SRA does not have a monitor for $\mathrm{CO}$ or $\mathrm{NO}_{2}$, I assign pollution values from the nearest SRA with a monitor to preserve sample size. I use measures of these pollutants that correspond with air quality standards for the dates of the analysis.

Because weather is correlated with ozone levels and may directly affect time spent

PSI is a nonlinear function of ppm, I convert the ozone forecast to ppm.

${ }^{15}$ I estimated models that also included an indicator for whether alerts are issued correctly, and found no significant differences in the estimates.

${ }^{16}$ Particulate matter (PM10) is unfortunately unavailable on a daily basis, but the high collinearity between PM10, 
outside and health, I control for numerous weather variables obtained from the Surface Summary of the Day (TD3200) from the National Climatic Data Center. Using the 30 weather stations available in SCAQMD, I assign daily maximum and minimum temperature and precipitation to each SRA in an analogous manner to pollution. For maximum relative humidity, sun cover, and resultant wind speed, there is only one weather station in SCAQMD with a complete history of this variable (Los Angeles International Airport), so I assign it to all SRAs within SCAQMD. These variables are also frequently missing, so to preserve sample size I impute the missing values using a best-subset regression with all other weather variables and ozone as covariates.

To assign information, pollution, and weather to individuals in the CHDD, I assign SRAs and AMAs to each individual using their ZIP code of residence, and merge the data by SRA or AMA and date. There are considerable disagreements over how to assign pollution from monitors to individuals. Using SRAs is justified on the grounds that SRAs were specifically designed to represent an area with common geography and pollution concerns, so there is a high degree of uniformity in ozone levels within an SRA. Each outdoor venue is linked to the pollution and weather station within its SRA by date as well.

\section{Conceptual Framework}

\section{A. Health Effects of Ozone}

To fix ideas on measuring and interpreting the effect of pollution on health, assume the following relationship between asthma and ozone:

(2) asthma $=f$ (ozone*avoidance, $S$ )

where avoidance is a measure of avoidance behavior, such as time spent outdoors, and $S$ are all other factors that affect health, such as medical services, exercise, existing health capital, and weather. Interacting ozone with avoidance behavior reflects exposure to pollution: ozone affects

CO, and NO2 should not bias estimates for ozone. 
people only if they are exposed to it. For example, if ozone is $0.20 \mathrm{ppm}$ and people spend no time outside (possibly because an alert is issued), then exposure to ozone is considerably less than if they spend time outside.

Imagine two experiments, both of which hold fixed $S$ but differ in how they treat outdoor time. In the first experiment, which is analogous to controlled-human exposure experiments, individuals are randomly assigned into one of two rooms, each containing different levels of ambient ozone. Individuals can not respond to the amount of ambient ozone in the room ( avoidance/dozone $=0$ ), so their exposure to ozone is identical to the ambient level of ozone. Because of random assignment, the difference in outcomes across the two groups

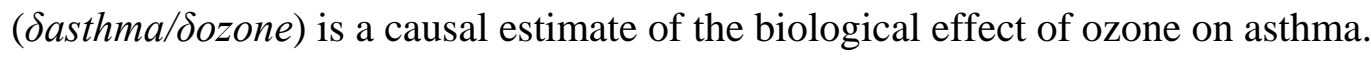

In the second experiment, which is analogous to quasi-experimental studies, individuals are randomly assigned to one of two locations, each containing different levels of ambient ozone. In contrast to the first experiment, people can respond to the amount of ambient ozone in their location, so their exposure to ozone is not necessarily identical to the ambient level of ozone. Since these responses are not held fixed, the measured effect of ozone on asthma

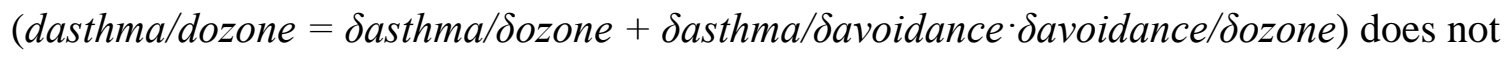
represent the biological effect. Because of random assignment, this is a causal estimate of the "behavioral" effect of ozone on asthma. If outdoor time is negatively correlated with ambient ozone levels, then the behavioral effect will represent a lower bound of the biological effect.

If any responses to ambient ozone in the second experiment can be properly accounted

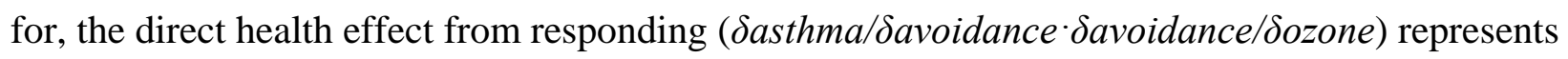
the "avoidance" effect. That is, it represents the effect from limiting exposure to ozone on asthma for a given level of ozone. Importantly, it can be used as an alternative way of examining 
whether ozone affects asthma - if people reduce their exposure to a pollutant and this causes an improvement in health, then the pollutant must affect health. Furthermore, accounting for avoidance behavior enables one to uncover the biological effect of ozone on asthma.

\section{B. Avoidance behavior ${ }^{17}$}

Individuals may substitute between indoor and outdoor activities because they believe exposure to outdoor pollution affects health and because of the direct utility they receive from spending time outside. People spend less time outside (increase avoidance behavior) when forecasted ozone increases if more time outside is worse for health when ozone is high, a reasonable condition because it is precisely what air quality information conveys. ${ }^{18}$ Susceptible people are more likely to respond to information if avoidance behavior is more productive for them, also a reasonable condition. If responses to information vary by susceptibility, then the bias in estimates of the health effect of ozone from omitting avoidance behavior will vary by susceptibility as well.

Although susceptible individuals are more likely to respond to air quality information in general, they may be less likely to respond to smog alerts per se. Smog alerts are widely disseminated, so the cost of acquiring this information is nearly zero. All individuals regardless of susceptibility - are encouraged to respond to alerts, so some unsusceptible individuals will respond to alerts if the expected benefits from responding outweigh the costs. Obtaining the ozone forecast, however, involves greater effort, so only those who benefit from avoiding ozone - the susceptible population - are likely to acquire that information. Since smog alerts are determined by the ozone forecast, then smog alerts offer no additional information once the ozone forecast is obtained. Therefore, susceptible individuals are less likely to respond

\footnotetext{
${ }^{17}$ Contact the author for a full derivation of the predictions described in this section.
} 
to an alert than unsusceptible individuals.

\section{Estimation Strategy}

There are two primary empirical objectives: to assess whether people respond to air quality information and, if they respond, to assess the bias from incorporating these responses. Although the empirical models are nested theoretically, I separately elaborate on empirical strategies for each equation because: 1) the data do not fully overlap since I only observe outdoor behavior for two locations in SCAQMD but hospital admissions for all of SCAQMD and 2) empirical concerns unique to each model require different identification strategies.

\section{$\underline{\text { A. Avoidance behavior }}$}

To estimate the effect of air quality information on attendance at each outdoor location, I focus on estimating the impact of smog alerts only and use the ozone forecast to identify the effect of smog alerts. Since alerts are a deterministic function of the forecasted ozone, as indicated in equation (1), forecasted ozone fully governs the alert selection rule and makes it possible to leverage a regression discontinuity $(\mathrm{RD})$ design. If days just below forecast ozone levels of $0.20 \mathrm{ppm}$ are otherwise identical to days just at or above 0.20 , then the discontinuity in attendance that occurs at $0.20 \mathrm{ppm}$ represents the causal effect of alerts. If people directly respond to the ozone forecast, this does not invalidate the empirical strategy - it will simply reduce the effect of alerts on attendance. Therefore, this design assesses whether people respond to the more simplistic and readily available information contained in alerts conditional on the continuous index being available.

To implement the RD, I estimate the following equation:

$$
\log \left(\text { attendance }_{t}\right)=\text { alert }_{t} \alpha_{1}+g\left(\text { ozone }_{t}^{f}, \alpha_{2}\right)+X_{t} \alpha_{3}+M_{t} \alpha_{4}+f(t)+\varepsilon_{t}
$$

\footnotetext{
18 A necessary condition for this to arise is that indoor ozone levels are considerably lower than outdoor levels, which evidence generally supports (Chang et al. 2000).
} 
where alert $_{t}$ is a dummy variable indicating whether a smog alert is issued in the AMA of the outdoor facility at day $t, g$ is a function that relates the ozone forecast (ozone $e^{f}$ ) to attendance, and $\varepsilon_{t}$ is an error term. $X_{t}$ are meteorological and pollution variables that affect quality of the day. $M_{t}$ are holiday, summer schedule, and day of week dummies to account for changes in leisure time. $f(t)$ is a set of year-month dummy variables to account for both seasonal and temporal patterns in solar radiation, pollution, and weather. If $\alpha_{1}<0$, this indicates outdoor attendance decreases when alerts are announced. Because the Observatory is open during the evening when ozone levels are lower and responses may be smaller there than at the Zoo, I estimate this model separately for both places. ${ }^{19}$

To allow for a flexible specification of $g$, I begin by estimating a specification linear in ozone forecast, as graphical evidence below suggests is plausible. Additionally, I control for $g$ non-parametrically by specifying a dummy variable for each value of the ozone forecast, but omit the smog alert variable. To infer the impact of alerts, I use the change in coefficients around the alert threshold by comparing the dummy variable on ozone $e^{f}=0.19$ to ozone $e^{f}=0.20$ ppm. If the dummy variable(s) above the alert threshold is lower than the one below the alert threshold, this implies a decrease in attendance in response to alerts. ${ }^{20}$

While it is impossible to know whether the unobservables are identical across alert status, I examine how well the observable covariates balance across alert status. Figure 1 shows a plot of three likely influential covariates (temperature, humidity, and CO) against ozone forecast levels. All three covariates evolve smoothly throughout this plot, suggesting they are unaffected by smog alerts. Given the observed factors balance, then it is more reasonable to believe the

\footnotetext{
${ }^{19}$ Since the covariate (ozone forecast) that determines the treatment (smog alert) is discrete, I compute standard errors clustered on each value of forecasted ozone (Card and Lee 2006).

${ }^{20}$ Results are robust to alternative specifications of $g$, such as restricting the sample to observations centered on the alert threshold (.15-.24 ppm).
} 
unobserved factors do as well.

As preliminary evidence that people respond to alerts, average attendance at the Zoo is also plotted in Figure 1. Focusing on the observations near 0.20 ppm, attendance is generally increasing in forecasted ozone prior to $0.20 \mathrm{ppm}$. At $0.20 \mathrm{ppm}$, the point at which an alert is issued, attendance sharply drops. After that, attendance remains increasing in forecasted ozone, but is generally lower than attendance below $0.20 \mathrm{ppm}$. This jump in attendance at the alert threshold, which is larger than any other jump in attendance, provides the first piece of evidence that people respond to smog alerts.

Two additional assumptions necessary to obtain unbiased estimates of $\alpha_{l}$ is that 1) alert status is not updated once actual levels of ozone are realized and 2) there are no supply-side effects. Despite the temptation to continuously update alert status, officials at SCAQMD indicate this is highly unlikely because of flaws inherent in detecting and disseminating an alert as it occurs. ${ }^{21}$ In terms of supply side effects, facilities do not lower their price to entice customers or keep animals inside to protect their health on alert days, suggesting this assumption is likely to be satisfied. It is possible, however, that a more crowded atmosphere provides less enjoyment because of longer waiting times, for example. If an alert reduces crowding so that unsusceptible people increase demand for these outdoor attractions, this will result in a downward bias in $\alpha_{1}$.

\section{B. Health Effects of Ozone}

To estimate the effect of ozone on health, one would ideally focus on a more detailed version of equation (2) that includes lagged values of ozone, outdoor time, and other appropriate

\footnotetext{
${ }^{21}$ For example, ozone typically peaks in the late afternoon, around 3:00 pm. The data is not received until an hour later, and if a violation is detected, it must be double-checked to ensure accuracy. At this point, which can be up to two hours after the violation first occurred, the media are first made aware. By the time this information is
} 
variables. This is not feasible because the data with health outcomes covers all of SCAQMD while the data for outdoor time is not at the individual level and only covers two particular places. Instead, I substitute the factors that affect outdoor time into equation (2) to estimate the following reduced form relationship:

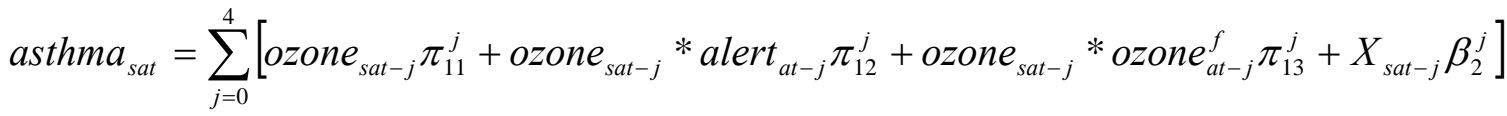

$$
\begin{aligned}
& +M_{t} \beta_{3}+f(t)+\sigma_{s}+v_{s a t}
\end{aligned}
$$

where $s, a$, and $t$ indexes SRA, AMA, and time, respectively, and $v_{\text {sat }}$ is the error term. ${ }^{22} h$ is the number of hospital admissions per day in each SRA. To remain consistent with previous ozone time-series studies that often found effects up to four days after exposure (Environmental Protection Agency 2006), I include four lags of ozone, information, and weather, but also assess sensitivity to alternative amounts of lags. $X, M$, and $f(t)$ are the same as equation (3) except I also include smog alerts and the ozone forecast in levels in $X$ to capture nuance effects associated with alerts being issued, such as individual over-reactions to alerts or hospitals increased willingness to admit patients because of an alert. $\sigma_{s}$ is an SRA fixed effect that accounts for observed and unobserved time invariant determinants of health within an SRA. Therefore, I compare changes in ozone levels and information with changes in hospitalizations within each month of the year and within an SRA.

The primary test of this analysis focuses on whether accounting for avoidance behavior affects estimates the biological effect of ozone on health. Instead of comparing the effect of each lag separately, I focus on the overall effect of ozone by computing the sum of the effect of ozone

disseminated and received by the public, sunlight has decreased and ozone levels have typically fallen to safer levels.

22 Smog alerts and the air quality forecast are included in levels in the vector $X$, described below. Although this equation should also contain ozone interacted with the other covariates ( $X$ and $M$ ), I omit the additional interactions to simplify exposition. Results with complete interactions, however, are nearly identical to results from this specification. 
across all lags, $\sum\left(\right.$ dasthma $_{\text {sat }} /$ oozone $\left._{\text {sat }-j}\right)=\sum\left(\pi_{11}^{j}+\overline{\text { alert }_{t-j}} \pi_{12}^{j}+\overline{\text { ozone }_{t-j}^{f}} \pi_{13}^{j}\right)$. If people respond to information about pollution and ozone affects health, then including smog alerts and the ozone forecast should increase estimates of the effect of ozone. To formally test this hypothesis, I estimate equation (4) both with and without controls for information about risk, and compare estimates via a Hausman test (Hausman 1978). ${ }^{23}$

The identification of ozone comes from daily variation in ozone levels within each year and month and within an SRA. To highlight this variation in ozone, Figure 2 plots the mean level of ozone for each day of the year. Immediately evident is the strong daily variation in ozone, which is likely to be orthogonal to diet, exercise, health care choices, pre-existing health stock, and numerous other factors that affect asthma hospital admissions. This figure also demonstrates the strong seasonal patterns in ozone that are necessary to account for because behavior and environmental conditions change throughout the year as well

In order to obtain precise estimates of the parameters of interest, it is essential that there is enough variation in ozone levels independent of seasonality, weather, co-pollutants, and all other variables included in these regressions. Figure 3 plots the mean residual variation in ozone for each day of the year after adjusting for $X, M$, year-month dummies and SRA fixed effects. This figure demonstrates substantial residual variation in ozone that is constant throughout the year, indicating seasonality is accounted for and ample variation for obtaining precise estimates.

A concern with using daily variation in ozone is the factors that drive this variation weather and ozone precursors - may directly affect health and not be observed in $X{ }^{24}$ With respect to weather, I control for temperature and sun cover - the two meteorological factors that

\footnotetext{
${ }^{23}$ The Hausman test statistic is given by $\left(\gamma^{s}-\gamma^{l}\right)^{\prime} *\left[\operatorname{var}\left(\gamma^{l}\right)-\operatorname{var}\left(\gamma^{s}\right)\right]^{-1} *\left(\gamma^{s}-\gamma^{l}\right) \sim \chi^{2}(q)$ where $\gamma^{s}$ is the estimated effect of ozone when excluding information from equation (4), $\gamma^{l}$ is the estimated effect of ozone when including information, and $q$ is the number of lags of ozone.
} 
affect ozone formation - directly in these regressions (as well as several other weather variables). Furthermore, I demonstrate below that estimates of the effect of ozone are insensitive to excluding all weather variables, suggesting confounding from weather is not a major concern. With respect to ozone precursors (NOx and VOCs), I can not directly include them in regression models because they are generally unavailable at the same level of detail, but it is unclear whether to control for them even if they are available. On one hand, these pollutants are not believed to be directly related to asthma, so any effect they might have on asthma is through their effect on ozone, which would dampen the estimated effect of ozone on health. On the other hand, the sources of NOx and VOC emissions may emit other pollutants that affect health. For example, automobiles emit benzene, which has been linked with asthma, in addition to NOx. Although I can not include all co-pollutants in the empirical models, I include $\mathrm{CO}$ and $\mathrm{NO}_{2}$ - two criteria pollutants linked with short-term respiratory health effects - and also demonstrate results are insensitive to excluding these co-pollutants.

As described in the conceptual framework, assessing the direct effect on information on asthma in equation (4) can be used as another test for understanding the health effects of ozone. If people respond to information and information has a negative effect on asthma hospitalizations, this implies ozone must affect health. For example, if individuals respond to alerts by reducing their exposure to ozone and their health improves, then ozone must affect health. Rather than focus on specific lags, I also use the sum across all lags: $\sum\left(\right.$ dasthma $_{\text {sat }} /$ dalert $\left._{\text {sat }-j}\right)=\sum\left(\overline{\text { ozone }_{t-j}} \pi_{12}^{j}\right), \sum\left(\right.$ asthma $_{\text {sat }} /$ oozone $\left._{\text {sat }-j}^{f}\right)=\sum\left(\overline{\text { ozone }_{t-j}} \pi_{13}^{j}\right)$ and jointly test whether the two parameters are different from zero. Smog alerts are identified by including the ozone forecast, akin to the RD design linear in forecasted ozone, which evidence

\footnotetext{
${ }^{24}$ This concern is also present in other epidemiological analyses that use daily time series.
} 
below indicates is a reasonable approximation for $g$. The ozone forecast is only identified if all factors that affect the ozone forecast, as specified in equation (1), are observed in equation (4). Although more tenuous than the assumption for the effect of smog alerts, it is a plausible assumption given the extensive controls for weather, solar radiation, and lagged ozone.

\section{Do People Respond to Smog Alerts?}

The first set of regression results, shown in Table 2, provides further evidence that people respond to smog alerts by decreasing outdoor activities. There is a separate panel for each outdoor facility, and each panel includes results from four specifications to gauge the sensitivity of estimates to both potential confounding and functional form assumptions of the RD. The odd numbered columns omit several variables likely to affect the demand for outdoor activities (precipitation, wind, humidity, observed ozone, carbon monoxide, and nitrogen dioxide), while the even numbered columns include them. ${ }^{25}$ Columns (1) and (2) use a linear specification for the RD and columns (3) and (4) are non-parametric estimates that specify a dummy variable for each forecasted ozone value.

Results for the Zoo are shown in Panel A. Columns (1) and (2) show a statistically significant drop in attendance of 15 percent both with and without the additional weather and air quality covariates. The non-parametric results in columns (3) and (4) indicate that smog alerts reduce attendance between 12 and 13 percent, quite similar to the parametric estimates. Moreover, the results are almost completely unaffected by excluding several important covariates, which is notable given that weather and observed ozone are important predictors of outdoor activities. This suggests that these variables evolve smoothly around the discontinuity, so the change in attendance at the discontinuity represents the causal effect of smog alerts.

Results for the Observatory, shown in Panel B, also show a decline in attendance from 
smog alerts. Attendance declines by roughly 3 percent in the parametric model, though statistically insignificant. In the non-parametric specification, there is a statistically significant drop in attendance of 6 percent, which is larger than the parametric estimates. Both estimates are also insensitive to including the weather and pollution variables. These results suggest a response to alerts, with the smaller magnitude than the Zoo consistent with the Observatory including night hours when ozone levels typically decrease.

I provide several sensitivity analyses to assess the robustness of these results. If the costs of avoiding these outdoor activities are lower for local residents, either because they are more aware of information or have lower costs of substitution, then they should display larger responses to alerts. Using the attendance breakdown at the Zoo, I explore how GLAZA members respond to alerts. Shown in column (1) of Table 3, GLAZA members reduce attendance by 19 percent, which is larger than the total attendance response. Given that GLAZA members are more likely to be local residents, this conforms to expectations that locals show a greater response to alerts than other attendees.

More susceptible people are more likely to display avoidance behavior, but they may be less likely to respond to alerts if they obtain the continuous ozone forecast. To assess this, I estimate equation (3) for the Zoo separately for children and the elderly, two susceptible groups. The results, shown in columns (2) through (4) of Table 3, indicate responses between 19 and 24 percent for children and seniors, also larger than the overall response. Although this basic classification of susceptibility is not sufficient for capturing those with a history of respiratory illness, it captures two major groups targeted by air quality information. In general, these results suggest the more simplified information contained in the alerts is valued by potentially susceptible populations.

${ }^{25}$ I do not omit temperature and sun cover because they are part of the ozone prediction model. 
I also provide several specification tests for this model, shown in Table 4. As a first test, I estimate regressions with the dependent variable in levels rather than logs, which holds constant the number of attendees, rather than percent of attendees, affected by alerts. Shown in column (1), the implied percentage drop in attendance is comparable in magnitude to the main results: Zoo attendance drops by 10 percent and Observatory attendance by 3 percent.

Second, I provide a falsification test by testing for a discontinuity where one should not exist. $^{26}$ Following Imbens and Lemiuex (2007), I use the sub-sample with no smog alerts (ozone forecasts less than $0.20 \mathrm{ppm}$ ), which avoids estimating a regression where a known discontinuity exists, and create an artificial discontinuity at the median ozone forecast, which maximizes the power of the test to find jumps. ${ }^{27}$ The results, shown in column (2), are not statistically significant, providing support for the model.

As a third check, I include future alerts in equation (3). People cannot respond to a forecasted alert before it occurs, so finding an effect would suggest misspecification. If people use a naïve version of equation (1) to forecast ozone on their own, however, then they may anticipate future smog alerts by increasing current outdoor activities, suggesting a positive coefficient on future alerts. Therefore, only a negative coefficient on future alerts would necessarily suggest misspecification. The results, shown in column (3) of Table 4, indicate a positive but statistically insignificant effect from future alerts for both facilities, hinting people may anticipate future smog alerts. Furthermore, the effects from contemporaneous alerts are unaffected by the inclusion of future alerts.

For a final specification check, I estimate the regression using an outcome that should not be affected by smog alerts. One concern with the evidence presented thus far is that people may

\footnotetext{
${ }^{26}$ Figure 2 also provides informal evidence that the largest jump in attendance occurs at $0.2 \mathrm{ppm}$.

${ }^{27}$ The median ozone forecast for this subsample is $0.11 \mathrm{ppm}$.
} 
respond to alerts out of altruistic rather than health concerns by driving less so as to not further contribute to pollution on days already considered highly polluted. Therefore, people may reduce visits to specific outdoor attractions but not limit total time outside, implying a decrease in outdoor attendance is not evidence of avoidance behavior. Since attending baseball games is a sedentary activity and typically at night when ozone levels are lower, attendance at Dodgers and Angels games should not be affected by alert status. Shown in column (4) of Table 4, smog alerts are not statistically significant for both teams, and the large point estimate for the Angels suggests, if anything, an increase in attendance, which is consistent with lower ozone levels at night. ${ }^{28}$ This finding helps to substantiate the overall evidence that people are displaying avoidance behavior in response to information about pollution.

Overall, these estimates suggest a significant drop in attendance from an alert. The results are extremely insensitive to functional form assumptions and potential confounding, and are of the same order of magnitude despite coming from distinct sources, making it unlikely these results are due to sampling variability or general misspecification. The results suggest people respond to smog alerts by reducing time spent outdoors.

\section{The Health Effects of Ozone}

Given the evidence that people respond to these alerts, I now turn to whether this impacts estimates of the effect of ozone on health by presenting both graphical and regression analyses.

\section{A. Graphical analysis}

The main finding of this analysis is depicted in Figure 4. This figure is a nonparametrically smoothed scatter plot of regression-adjusted asthma hospitalizations against once

\footnotetext{
${ }^{28}$ Results are nearly identical when using only night games. As an additional test, if people drive less in response to alerts, then CO levels -- a proxy for traffic because it primarily comes from automobiles -- should fall at the alert threshold. As shown in Figure 2, however, CO evolves smoothly through the alert threshold, rejecting the altruism effect.
} 
lagged observed ozone levels. ${ }^{29}$ I focus on one lag here because previous studies have found the 1-day lag to have the largest effect on hospital admissions (Environmental Protection Agency 2006), though regressions below include several lags simultaneously. To assess the impact of avoidance behavior, I plot two separate lines. The first line ignores avoidance behavior by plotting asthma and observed ozone levels for all days regardless of whether a smog alert is issued. The second line accounts for avoidance behavior by limiting the plot to days where no smog alerts occur - so people could not have displayed avoidance behavior in response to an alert. If people respond to alerts and ozone affects health, then the second line should be higher than the first line.

The results for children (Figure 4A) confirm the importance of avoidance behavior. For lower levels of ozone, the two lines mirror each other, which is as expected because alerts, and therefore avoidance behavior, are unlikely at such low levels of realized ozone. Once ozone crosses $0.1 \mathrm{ppm}$ and smog alerts become more common, however, the two lines diverge. ${ }^{30}$ The relationship between ozone and hospitalizations flattens out considerably when ignoring smog alerts, which is consistent with avoidance behavior: as pollution levels rise, individuals protect themselves by reducing exposure, so increases in ambient ozone do not lead to increases in illness. Accounting for smog alert status, however, paints an entirely different picture; it shows a positive and linear relationship between ozone and asthma throughout the entire range of ozone. As ozone increases and alerts become more common, the line accounting for avoidance behavior is considerably higher than the one ignoring it. Although both lines support an effect of ozone on health, the line ignoring behavior substantially understates the effect.

\footnotetext{
${ }^{29}$ Asthma is regression-adjusted using all covariates in the regression analysis except for observed ozone and information about ozone. The smoothing is performed using locally weighted regression (LOWESS) procedures with a bandwidth of 0.4 and running-line least squares smoothing.
} 
The results for adults (Figure 4B) suggest avoidance behavior does not bias estimates for this age group. The two lines are nearly indistinguishable from each other, showing a positive, linear relationship between ozone and asthma throughout the entire range of ozone. This suggests adults do not engage in avoidance behavior in response to an alert, which is consistent with results from Table 3 indicating that children and elderly Zoo attendees show greater responses to alerts than adults.

\section{B. Regression results}

Regression estimates (shown in Table 5), which extend the graphical analysis by allowing for contemporaneous and several lags of ozone and other environmental confounders, support the graphical relationship from Figure 4. For children, estimates of the effect of ozone that omit air quality information in column (1) indicate that a $0.01 \mathrm{ppm}$ increase in the 5-day average ozone leads to a statistically significant 1.09 percent increase in hospital admissions. When controlling for smog alerts and the ozone forecast, estimates in column (2) indicate a 0.01 ppm increase in the 5-day average ozone leads to a statistically significant 2.88 percent increase in hospital admissions, which is 2.6 times larger than estimates that ignore information, a statistically significantly difference according to the Hausman test. Furthermore, alerts have a statistically significant and negative effect on hospitalizations, suggesting a reduction in exposure to ozone via smog alerts improves health. These results are consistent with the hypothesis that families protect this vulnerable segment of the population, and this behavior affects the estimated relationship between ozone and health.

Also consistent with the graphical results, estimates for adults ages 20-64 are unaffected by controls for information about pollution, shown in columns (3) and (4). Estimates of the

\footnotetext{
${ }^{30}$ The two lines diverge below $0.2 \mathrm{ppm}$ because smog alerts are based on forecasted ozone while this plot is based on observed ozone.
} 
effect of ozone are statistically significant in both specifications, and controlling for information does not affect these estimates according to the Hausman test. Estimates with controls for information indicate a $0.01 \mathrm{ppm}$ increase in the 5-day average ozone leads to a 2.08 percent increase in hospital admissions, which is slightly smaller than the effect on children. Consistent with information not impacting the estimates for ozone, information has no direct effect on health. This suggests adults do not respond to this information in sufficient volume to affect the estimated relationship between ozone and health.

For the elderly, shown in columns (5) and (6), the effect of ozone is statistically significant in both specifications. Estimates are 40 percent larger with controls for both alerts and the ozone forecasts (column (6)) than estimates without controls for information (column (5)), which is significantly different at the 10 percent level according to the Hausman test. A $0.01 \mathrm{ppm}$ increase in the 5-day average increases asthma admissions by 2.66 percent, which is close to the effect for children. Although neither source of information is statistically significant at conventional levels, the ozone forecast is statistically significant at 15 percent, suggesting the ozone forecast is the more important piece of information for the elderly. Overall, these results imply the elderly display avoidance behavior, though its impact on estimates is smaller than the impact for children.

To gauge the magnitude of these effects, I calculate the savings in asthma hospital costs for children only from a uniform $0.01 \mathrm{ppm}$ decrease in the 5-day average ozone in all SRAs in SCAQMD using estimates from columns (1) and (2) in Table 4. Using estimates from column (1) and valuing an asthma admission at the mean hospital bill for asthma (\$7301), a $0.01 \mathrm{ppm}$ decrease yields savings of roughly $\$ 157,727$ per smog alert season. ${ }^{31}$ Controlling for

${ }^{31} 157,727=22 *(0.4008 / 100) * 245 * 7301$, where 22 is the number of SRAs used in the analysis, 0.4008 is the effect from a one ppm decrease in ozone, and 245 is the number of days per smog alert season. 
information about pollution increases this estimate considerably to $\$ 417,717 .^{32}$ The difference of roughly $\$ 260,000$ between these estimates for children suggest the importance of accounting for avoidance behavior, though it represents a lower bound of this difference because it ignores any direct effects on well-being not included in hospital costs and it ignores health episodes other than asthma hospitalizations. Therefore, the estimated difference in costs understates the full difference in social benefits associated with reductions in ozone levels.

\section{Sensitivity Analyses}

In Table 6, I assess the sensitivity of estimates to the number of lags included in the regression. I begin with a model containing only contemporaneous ozone, information, and weather, and then consecutively add one lag at a time, with the final specification including six lags. For children, in the model without controls for avoidance behavior, the effect of ozone is monotonically increasing from zero to three lags, and levels out after that, generally consistent with prior evidence. With controls for avoidance behavior, the effect of ozone is monotonically increasing even through lag 6 , suggesting more lags than is typically used may be necessary for capturing the full health effects of ozone on children. For adults and the elderly, three and four lags appear to sufficiently capture all of the health effects, respectively, regardless of whether avoidance behavior is controlled for.

In table 7, I present a series of specification checks to assess the likelihood of timevarying unobserved heterogeneity. As previously mentioned, ozone is correlated with weather and other pollutants that may affect health but not be fully captured in these models. As a crude test, I estimate models that do not control for weather and other pollutants. If estimates are insensitive to excluding these variables, this increases confidence that there is no remaining confounding. These estimates, shown in Panel A (excluding weather) and B (excluding co-

\footnotetext{
${ }^{32}$ Comparable calculations for the elderly are $\$ 219,781$ and $\$ 305,392$, respectively.
} 
pollutants) of Table 7, confirm that the effects of ozone are generally unaffected by these variables, lending support to the empirical methodology.

I also estimate models using only emergency room (ER) admissions as the dependent variable. Hospital admissions for asthma can be pre-arranged and may not reflect the effect of exposure to ozone, while ER admits, which are roughly 60 percent of all hospital admits for asthma, are unplanned episodes that are more likely to be an immediate reaction to ozone. The results, shown in Panel C of Table 7, indicate estimates are insensitive to this alternative measure - although coefficients are smaller, it has a comparable percentage effect on ER admissions as hospital admissions.

As a general specification check, I add future pollution levels, information, and weather to the model. Ozone and information in the future cannot affect health today, so any effect would suggest misspecification of the model. To maintain balance with the lagged structure of the model, I add five leads of ozone and information along with the appropriate interaction terms, and separately test the joint significance of the biological and avoidance effect. The results, shown in Panel D of Table 7, reveal quite comparable effects of ozone and information as in Table 5 for all ages and no statistically significant effect from future alerts and ozone, providing general validation to the specification.

\section{Conclusion}

This paper finds that individuals in Southern California respond to information about pollution by reducing time spent outside, and this significantly impacts estimates of the relationship between ozone and health for susceptible populations. If people change their behavior in response to this information, this action must have some costs to them. Given that 
providing information about pollution is a growing part of environmental policy, ${ }^{33}$ measuring these costs is essential for designing optimal policy and should be a focus of future research.

There are two important caveats to this study. First, Southern California has a unique history of smog and ozone, so the results may not necessarily generalize to other contexts. Although numerous cities provide various types of air quality forecasts, they are typically less publicized than in Southern California. Furthermore, forecasting pollutants other than ozone is inherently more difficult, so information is less prevalent and reliable for other pollutants. In both cases, less information leads to less avoidance behavior, and less potential bias in estimates.

The second caveat is there may be additional sources of private information about pollution. Although ozone is not directly visible, it is a major component of smog, which is visible. There is no evidence to indicate whether people respond to this information, but if the bias from omitting this information is in the same direction as the bias from omitting public information, then current estimates of the biological effect would remain underestimates of the true effect.

\section{References}

Ahituv, Avner, V. Joseph Hotz, and Tomas Philipson. 1996. "The Responsiveness of the Demand for Condoms to the Local Prevalence of AIDS.” Journal of Human Resources 31(4): 869-97.

Bell, Michelle, Aidan McDermott, Scott Zeger, Jonathan Samet, and Francesca Dominici. 2004. “Ozone and Short-Term Mortality in 95 US Urban Communities, 1987-2000.” Journal of American Medical Association 292: 2371-2378.

Bresnahan, Brian, Mark Dickie, and Shelby Gerking. 1997. "Averting Behavior and Urban Air Pollution.” Land Economics 73: 340-357.

Brunekreef, Bert and Stephen Holgate. 2002. “Air Pollution and Health.” Lancet 360: 1233-42.

Card, David and David Lee. 2006. "Regression Discontinuity Inference with Specification Error.” NBER Technical Working Paper \#322.

Chang L., Petros Koutrakis, Paul Catalano, and Helen Suh. 2000. "Hourly Personal Exposures to Fine Particles and Gaseous Pollutants." Journal of the Air and Waste Management Association 50(7): 1223-35.

\footnotetext{
33 Similar pollution warning systems have been implemented in, for example, Arkansas, Texas, Baltimore, Washington, New York, Oklahoma, Kansas, and Chicago.
} 
Chay, Kenneth and Michael Greenstone. 2003a. “Air Quality, Infant Mortality, and the Clean Air Act of 1970.” NBER Working Paper \#10053.

Chay, Kenneth and Michael Greenstone. 2003b. "The Impact of Air Pollution on Infant Mortality: Evidence from Geographic Variation in Pollution Shocks Induced by a Recession.” Quarterly Journal of Economics 118(3): 1121-1167.

Currie, Janet and Matthew Neidell. 2005. "Air Pollution and Infant Health: What Can We Learn from California’s Recent Experience?” Quarterly Journal of Economics 120(3): 10031030.

Dockery, Douglas, C. Arden Pope, Xiping Xu, John Spengler, James Ware, Martha Fay, Benjamin Ferris, and Frank Speizer. 1993. "An Association between Air Pollution and Mortality in Six U.S. Cities.” New England Journal of Medicine 329:1753-1759.

Environmental Protection Agency. 1999. "Guidelines for Reporting of Daily Air Quality - Air Quality Index (AQI).” EPA Document \#454-R-99-010, Research Triangle Park, NC. . 2006. Air Quality Criteria Document for Ozone. Washington, DC: Environmental Protection Agency.

Friedman, Michael, Kenneth Powell, Lori Hutwagner, LeRoy Graham, and W. Gerald Teague. 2001. "Impact of Changes in Transportation and Commuting Behaviors During the 1996 Summer Olympic Games in Atlanta on Air Quality and Childhood Asthma.” Journal of the American Medical Association 285: 897-905.

Garty, Ben Zion, Evsey Kosman, Eli Ganor, Victor Berger, Limor Garty, Tova Wietzen, Yesheskel Waisman, Mark Mimouni, and Yozv Waisel. 1998. "Emergency Room Visits of Asthmatic Children, Relation to Air Pollution, Weather, and Airborne Allergens.” Annals of Allergy, Asthma, and Immunology 81(6): 563-70.

Hausman, Jerry. 1978. "Specification Tests in Econometrics” Econometrica 46: 1251-1271. Heinrich, Joachim, Bernd Hoelscher, and H. Erich Wichmann. 2000. "Decline of Ambient Air Pollution and Respiratory Symptoms in Children.” American Journal of Respiratory and Critical Care Medicine 161: 1930-1936.

Imbens, Guido and Thomas Lemieux. 2007. "Regression Discontinuity Designs: A Guide to Practice.” NBER Technical Working Paper 337

Ippolito, Pauline and Alan Mathios. 1990. "Information, Advertising and Health Choice: A Study of the Cereal Market.” Rand Journal of Economics 21:459-480.

Jayachandran, Seema. 2005. “Air Quality and Infant Mortality during Indonesia’s Massive Wildfires in 1997.” Mimeograph, UCLA.

Jin, Ginger and Philip Leslie. 2003. "The Effect of Information on Product Quality: Evidence from Restaurant Hygiene Grade Cards.” Quarterly Journal of Economics 118(2): 409451.

Katsouyanni, Klea, Joel Schwartz, C. Spix, Giota Touloumi, Zmirou D, Zanobetti A, Wojtyniak B, Vonk JM, Tobias A, Ponka A, Sylvia Medina, Bacharova Ljuba, and Ross Anderson. 1996. "Short Term Effects of Air Pollution on Health: A European Approach Using Epidemiologic Time Series Data: The APHEA Protocol.” Journal of Epidemiology and Community Health 50(Suppl 1): S12-8.

Kinney, Patrick, George Thurston, and Mark Raizenne. 1996. "The Effects of Ambient Ozone on Lung Function in Children: A Reanalysis of Six Summer Camp Studies.” Environmental Health Perspectives 104(2): 170-4.

Lederman, Sally Ann, Virginia Rauh, Lisa Weiss, Janet Stein, Lori Hoepner, Mark Becker, and Frederica Perera. 2004. "The Effects of the World Trade Center Event on Birth Outcomes 
among Term Deliveries at Three Lower Manhattan Hospitals." Environmental Health Perspectives 112(17): 1772-1778.

Levy, Jonathan, Timothy Carrothers, Jouni Tuomisto, James Hammitt, and John Evans. 2001. "Assessing the Public Health Benefits of Reduced Ozone Concentrations."

Environmental Health Perspectives 109(12): 9-20.

Lierl, Michelle and Richard Hornung. 2003. "Relationship of Outdoor Air Quality to Pediatric Asthma Exacerbations.” Annals of Allergy, Asthma, and Immunology 90(1): 28-33.

Lleras-Muney, Adriana. 2005. "The Needs of the Army: Using Compulsory Relocation in the Military to Estimate the Effect of Environmental Pollutants on Children's Health.” Mimeograph, Princeton University.

Mullahy, John. 1999. "It'll Only Hurt a Second? Microeconomic Determinants of Who Gets Flu Shots." Health Economics 8(1): 9-24.

Neidell, Matthew. 2004. "Air Pollution, Health, and Socio-Economic Status: The Effect of Outdoor Air Quality on Childhood Asthma.” Journal of Health Economics 23(6): 12091236.

Norris, Gary, Sharon YoungPong, Jane Koenig, Timothy Larson, Lianne Sheppard, and James Stout. 1999. "An Association between Fine Particles and Asthma Emergency Department Visits for Children in Seattle.” Environmental Health Perspectives 107(6): 489-493.

Philipson, Tomas. 1996. "Private Vaccination and Public Health: An Empirical Examination for U.S. Measles.” Journal of Human Resources 31(3): 611-30 . 2000. "Economic Epidemiology and Infectious Diseases." In Handbook of Health Economics, Vol I, eds. Anthony Cuyler and Joseph Newhouse, 1761-1799. NorthHolland.

Pope, C. Arden. 1989. "Respiratory Disease Associated with Community Air Pollution and a Steel Mill, Utah Valley.” American Journal of Public Health 79: 623-628.

Pope, C. Arden, Joel Schwartz, and Michael Ransom. 1992. "Daily Mortality and PM10 Pollution in Utah Valley." Archives of Environmental Health 47: 211-216.

Pope, C. Arden, Michael Thun, M.M. Namboodiri, Douglas Dockery, John Evans, Frank Speizer and Clark Heath Jr. 1995. "Particulate Air Pollution as a Predictor of Mortality in a Prospective Study of U.S. Adults.” American Journal of Respiratory and Critical Care Medicine 151(3): 669-674.

Ransom, Michael, and C. Arden Pope. 1995. "External Health Costs of a Steel Mill." Contemporary Economic Policy 13: 86-97.

Schwartz, Joel. 1995. "Air Pollution and Hospital Admissions for the Elderly in Detroit, Michigan.” American Journal of Respiratory and Critical Care Medicine 150(3): 648655.

Smith, V. Kerry, and Reed Johnson. 1988. "How Do Risk Perceptions Respond to Information? The Case of Radon.” Review of Economics and Statistics 70(1): 1-8.

Sneeringer, Stacy. 2006. "Pollution and Infant Health.” Mimeograph, Wesleyan University.

Thurston, George, Kazuhiko Ito, Patrick Kinney, and Morton Lippmann. 1992. "A multi-year study of air pollution and respiratory hospital admissions in three New York State metropolitan areas: results for 1988 and 1989 summers." Journal of Exposure Analysis and Environmental Epidemiology 2(4):429-50.

Wilson, Richard and John Spengler. 1996. Particles in Our Air: Concentration and Health Effects. Cambridge, MA: Harvard University Press 
Figure 1. Zoo Attendance and Covariates by Ozone Forecast

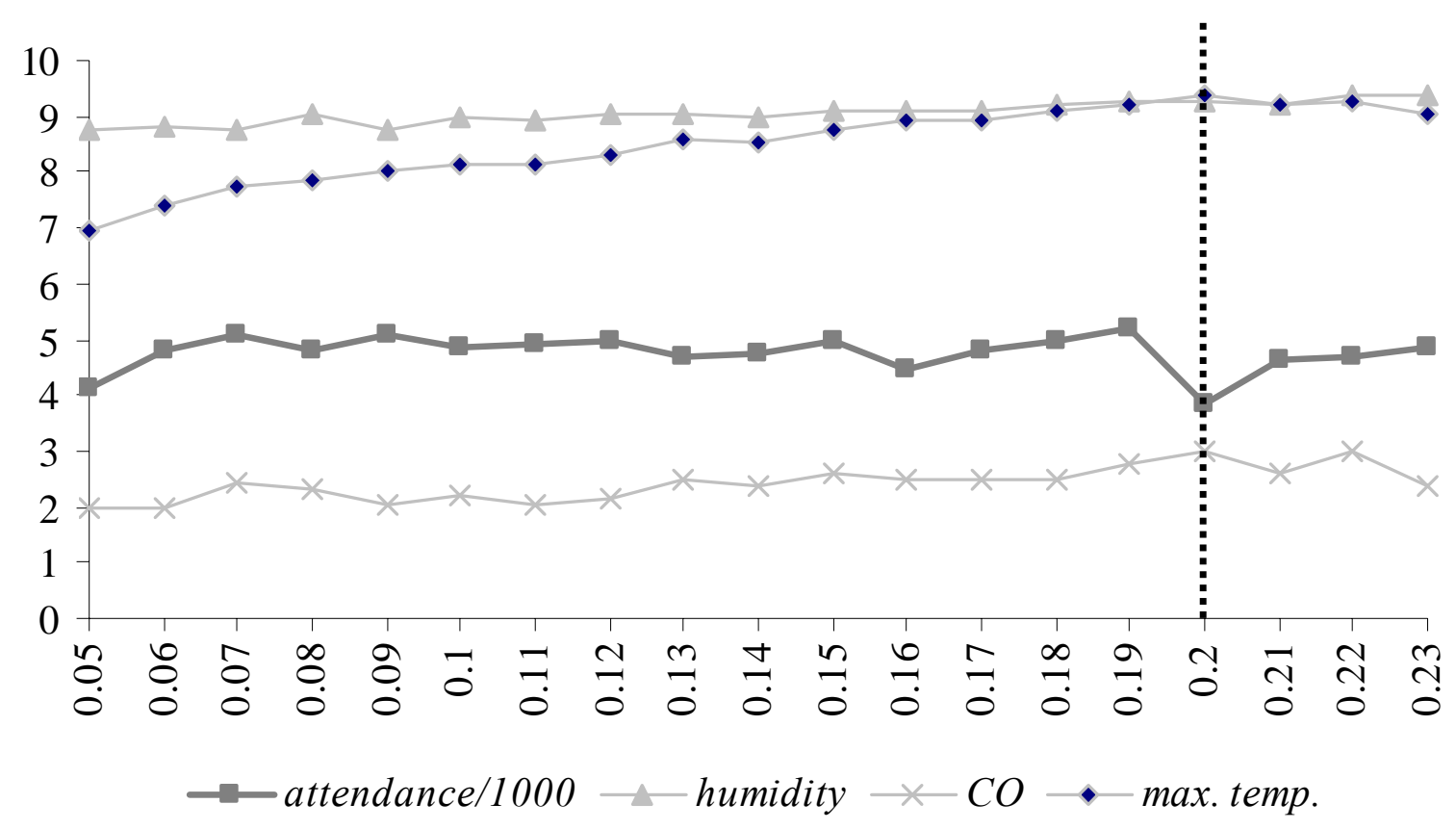


Figure 2. Variation in 1-hour Ozone by Day of Year

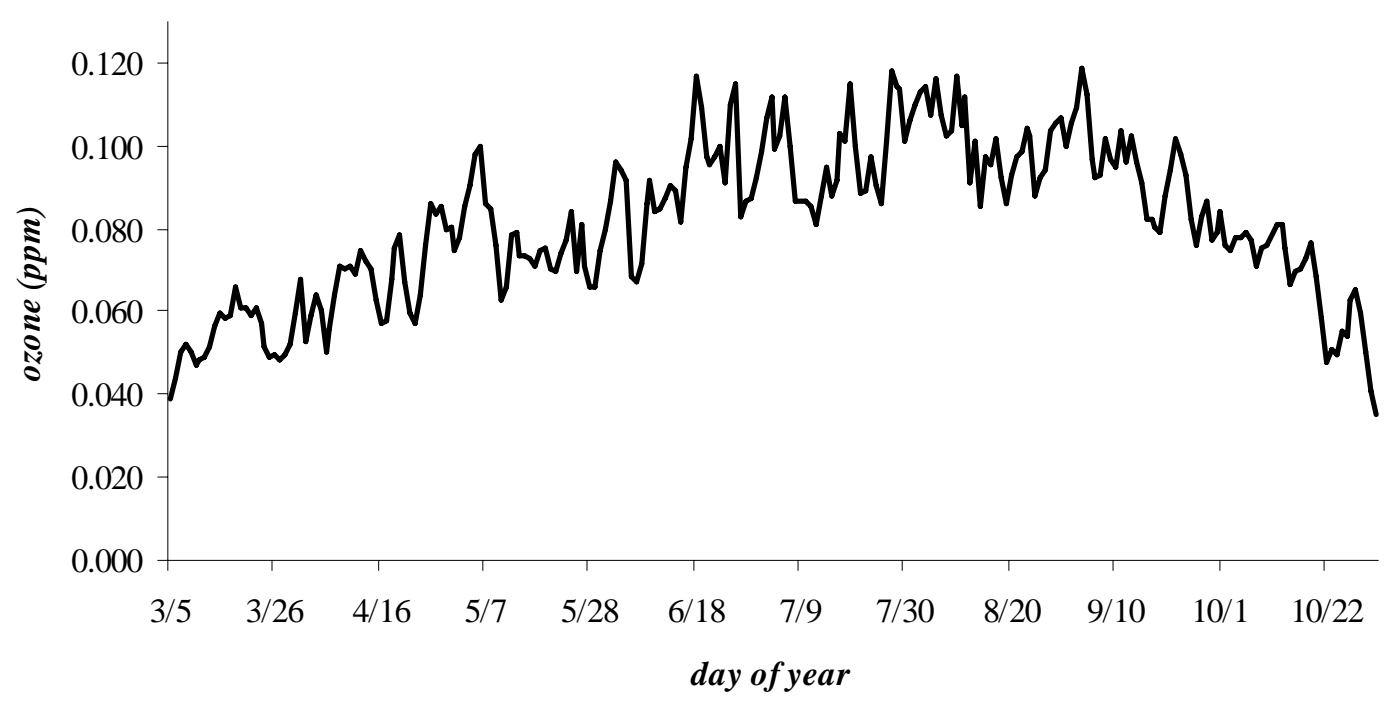

Figure 3. Residual Variation in 1-hour Ozone by Day of Year

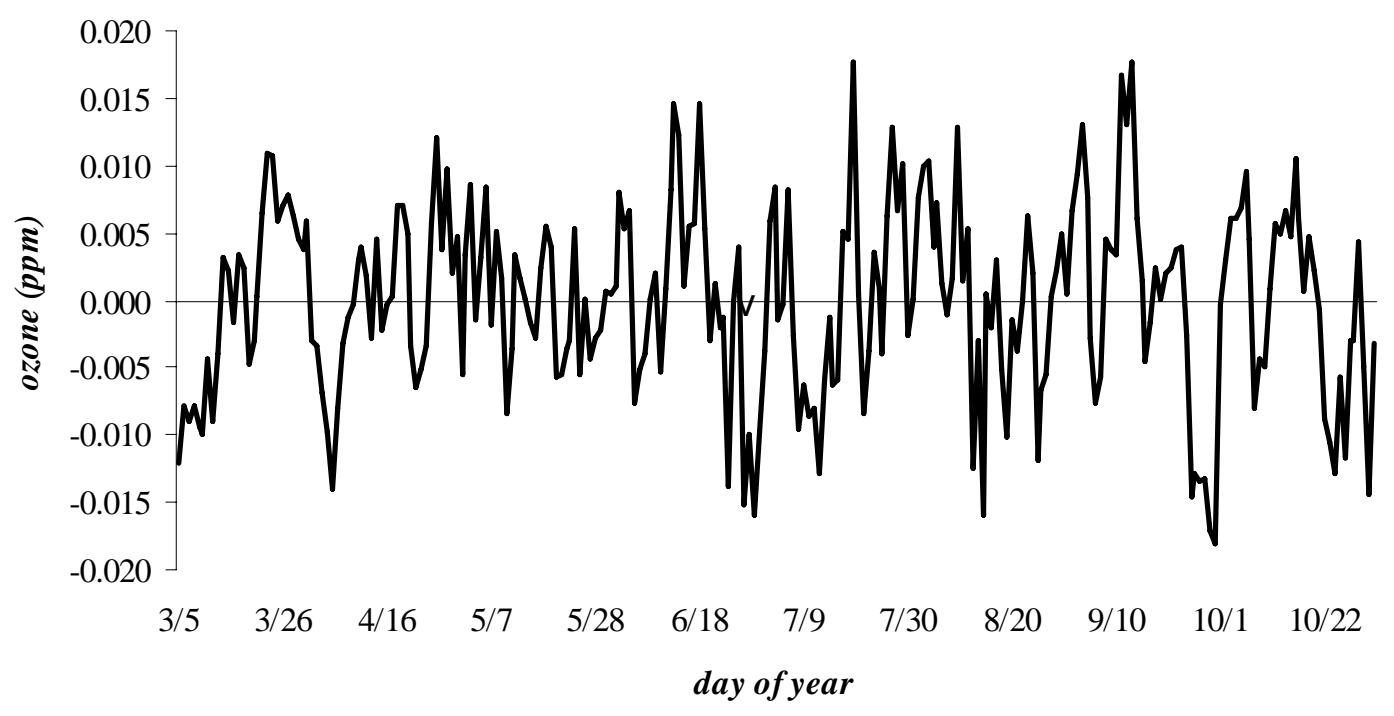


Figure 4. Adjusted Asthma Hospital Admissions by Age on Lagged Ozone by Alert Status

A. Age 5-19

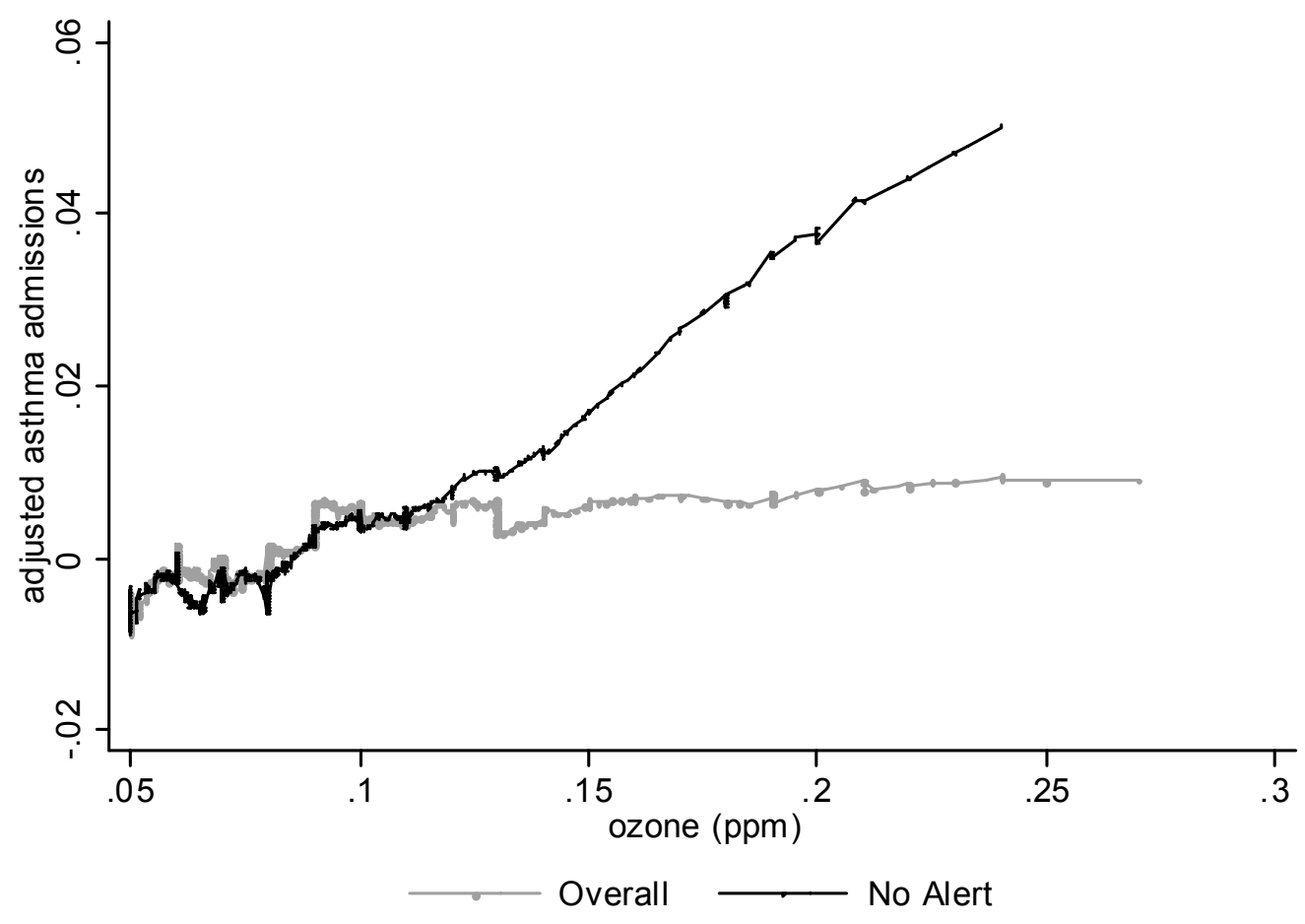

B. Age 20-64

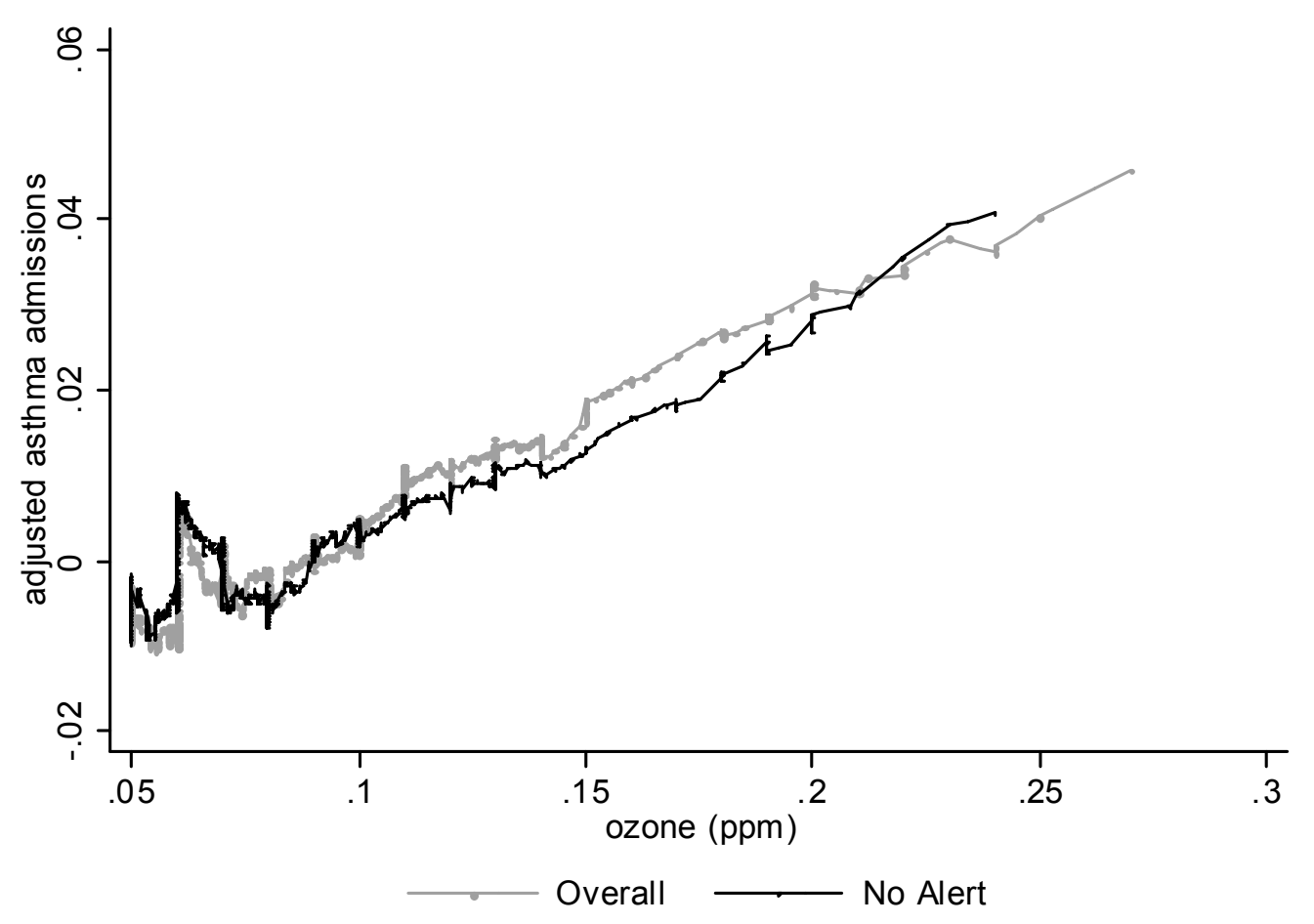


Table 1. Summary statistics

\section{A. Daily attendance}

\begin{tabular}{lcc} 
& mean & std. dev. \\
\hline Zoo $(n=1949)$ & 4766 & 3160 \\
children $<2$ & 299 & 362 \\
children 2-12 & 766 & 774 \\
seniors & 81 & 51 \\
adult & 1530 & 1655 \\
GLAZA members & 718 & 538 \\
Observatory $(n=1770)$ & 5629 & 2368 \\
Dodgers $(n=574)$ & 37886 & 8012 \\
Angels $(n=655)$ & 26679 & 9042
\end{tabular}

\section{B. Daily asthma hospital admissions}

\begin{tabular}{lcc} 
age group & per SRA & per SCAQMD \\
\hline $5-19$ & 0.369 & 9.007 \\
$20-64$ & 0.737 & 17.995 \\
$65+$ & 0.292 & 7.165
\end{tabular}

\section{Alert accuracy}

\begin{tabular}{lcc} 
year & Zoo & SCAQMD \\
\hline 1989 & $16 / 6 / 9$ & $169 / 56 / 89$ \\
1990 & $12 / 2 / 5$ & $118 / 28 / 54$ \\
1991 & $20 / 4 / 8$ & $142 / 34 / 50$ \\
1992 & $24 / 2 / 8$ & $140 / 39 / 42$ \\
1993 & $10 / 2 / 1$ & $84 / 23 / 20$ \\
1994 & $15 / 3 / 2$ & $107 / 14 / 20$ \\
1995 & $7 / 0 / 1$ & $32 / 3 / 5$ \\
1996 & $0 / 0 / 1$ & $16 / 0 / 6$ \\
1997 & $0 / 0 / 0$ & $3 / 0 / 1$ \\
Total & $104 / 19 / 35$ & $811 / 197 / 287$ \\
\hline
\end{tabular}

number of alerts issued / number of alerts correct / number of alerts missed

\section{Independent variables}

\begin{tabular}{lcccc} 
& \multicolumn{2}{c}{ Zoo } & \multicolumn{2}{c}{ SCAQMD } \\
variable & mean & std. dev. & mean & std. dev. \\
\hline alert & 0.053 & 0.225 & 0.071 & 0.257 \\
Ozone 1-hour $(\mathrm{ppm})$ & 0.078 & 0.038 & 0.082 & 0.043 \\
ozone 1-hour if alert $=1$ & 0.129 & 0.037 & 0.149 & 0.046 \\
ozone 1-hour forecast $(\mathrm{ppm})$ & 0.115 & 0.046 & 0.108 & 0.050 \\
maximum temperature $\left({ }^{\circ} \mathrm{F}\right)$ & 82.15 & 9.70 & 81.91 & 10.84 \\
precipitation (inches) & 0.218 & 1.617 & 0.200 & 1.546 \\
relative humidity $(\%)$ & 89.75 & 7.11 & 89.76 & 7.30 \\
average cloud cover sunrise to sunset $(\%)$ & 0.450 & 0.298 & 0.443 & 0.297 \\
resultant wind speed $(\mathrm{mph})$ & 5.66 & 2.37 & 5.70 & 2.37 \\
carbon monoxide 8-hour $(\mathrm{ppm})$ & 2.310 & 1.237 & 1.762 & 1.067 \\
nitrogen dioxide 1-hour $(\mathrm{ppm})$ & 0.073 & 0.032 & 0.062 & 0.029
\end{tabular}


Table 2. Regression estimates of smog alerts on attendance

\begin{tabular}{|c|c|c|c|c|}
\hline \multirow{2}{*}{\multicolumn{5}{|c|}{$\begin{array}{ccc}1 & 2 & 3 \\
\text { A. Dependent variable }=\log (\text { daily attendandance) } & \text { at Los Angeles Zoo }\end{array}$}} \\
\hline & & & & \\
\hline \multirow[t]{2}{*}{ alert } & $-0.148^{* *}$ & $-0.150^{* *}$ & $-0.122^{* *}$ & $-0.129 * *$ \\
\hline & {$[0.036]$} & {$[0.040]$} & [0.013] & [0.014] \\
\hline Controls for weather & $\mathrm{N}$ & $\mathrm{Y}$ & $\mathrm{N}$ & $\mathrm{Y}$ \\
\hline Observations & 1949 & 1949 & 1949 & 1949 \\
\hline \multicolumn{5}{|c|}{ B. Dependent variable $=\log ($ daily attendandance) at Griffith Park Observatory } \\
\hline \multirow[t]{2}{*}{ alert } & -0.032 & -0.031 & $-0.061^{* *}$ & $\overline{-0.059 * *}$ \\
\hline & [0.023] & [0.022] & [0.013] & {$[0.014]$} \\
\hline Controls for weather & $\mathrm{N}$ & $\mathrm{Y}$ & $\mathrm{N}$ & $\mathrm{Y}$ \\
\hline Observations & 1770 & 1770 & 1770 & 1770 \\
\hline
\end{tabular}

* significant at $5 \% ;{ }^{* *}$ significant at $1 \%$. Standard errors clustered on ozone forecast in brackets. Columns 1 and 2 include a linear term for ozone forecast and columns 3 and 4 include a separate dummy variable for each ozone forecast using the entire sample. In columns 1 and 2 , alert is a dummy variable equal to 1 if the ozone forecast is at least $0.2 \mathrm{ppm}$. In columns 3 and 4 , alert is the coefficient on ozone forecast $=0.2 \mathrm{ppm}$ minus the coefficient on ozone forecast $=0.19 \mathrm{ppm}$. All regressions include a quadratic in maximum temperature, percent of sun cover, an indicator for holiday, an indicator for summer schedule, day of week dummies and year-month dummies. Controls for weather include observed ozone, precipitation, resultant wind speed, maximum relative humidity, carbon monoxide, and nitrogren dioxide.

Table 3. Regression estimates of smog alerts on Zoo attendance by demographic

\begin{tabular}{ccccc} 
& 1 & 2 & 3 & 4 \\
& GLAZA members & Children $<2$ & Children 2-12 & Seniors \\
\hline alert & $-0.193^{* *}$ & $-0.222^{* *}$ & $-0.236^{* *}$ & $-0.194^{* *}$ \\
& {$[0.054]$} & {$[0.061]$} & {$[0.061]$} & {$[0.042]$} \\
\hline
\end{tabular}

See notes to Table 2. There are 1949 observations in all models. The specification in each column is comparable to the linear RD model from column 2 in Table 2. 
Table 4. Specification checks of estimates of smog alerts on attendance

$\begin{array}{llll}1 & 2 & 3 & 4\end{array}$

\begin{tabular}{|c|c|c|c|c|}
\hline & Dep. Var. in Levels & False Alert & Future Alert & Unaffected Activity \\
\hline \multirow{4}{*}{$\begin{array}{l}\text { Attendance at: } \\
\text { alert }\end{array}$} & Zoo & Zoo & Zoo & Dodgers \\
\hline & $-476.194^{*}$ & -0.017 & $-0.147^{* *}$ & 0.014 \\
\hline & [201.902] & {$[0.035]$} & {$[0.040]$} & {$[0.089]$} \\
\hline & $\{0.100\}$ & & & \\
\hline \multirow[t]{2}{*}{ future alert } & & & 0.031 & \\
\hline & & & [0.045] & \\
\hline Observations & 1949 & 1845 & 1898 & 574 \\
\hline \multirow{4}{*}{$\begin{array}{l}\text { Attendance at: } \\
\text { alert }\end{array}$} & Observatory & Observatory & Observatory & Angels \\
\hline & -146.114 & -0.016 & -0.034 & 0.105 \\
\hline & {$[90.748]$} & {$[0.032]$} & [0.023] & [0.149] \\
\hline & $\{0.026\}$ & & & \\
\hline \multirow[t]{2}{*}{ future alert } & & & 0.032 & \\
\hline & & & [0.031] & \\
\hline Observations & 1770 & 1671 & 1723 & 655 \\
\hline
\end{tabular}


Table 5. Regression estimates of ozone and avoidance behavior on asthma hospitalizations by age

\begin{tabular}{|c|c|c|c|c|c|c|}
\hline & 1 & 2 & 3 & 4 & 5 & 6 \\
\hline ozone (sum of lags) & $0.401^{*}$ & $1.061^{* *}$ & $1.356^{* *}$ & $1.532^{* *}$ & $0.558^{\star *}$ & $0.776^{* \star}$ \\
\hline & [0.185] & [0.245] & [0.254] & [0.335] & {$[0.158]$} & {$[0.208]$} \\
\hline & $\{1.09\}$ & $\{2.88\}$ & $\{1.84\}$ & $\{2.08\}$ & $\{1.91\}$ & $\{2.66\}$ \\
\hline Hausman test $\left(\mathrm{X}_{2}\right)$ & & 20.45 & & 0.74 & & 2.92 \\
\hline Prob $>x_{2}$ & & 0.00 & & 0.39 & & 0.09 \\
\hline alerts (sum of lags) & & $-0.162^{* *}$ & & -0.039 & & -0.014 \\
\hline & & {$[0.057]$} & & [0.078] & & [0.049] \\
\hline PSI (sum of lags) & & 0.013 & & -0.019 & & -0.037 \\
\hline & & [0.031] & & [0.042] & & {$[0.026]$} \\
\hline $\mathrm{F}($ alerts, $\mathrm{PSI})=0$ & & 5.41 & & 0.59 & & 2.16 \\
\hline Prob $>$ F & & 0.00 & & 0.55 & & 0.12 \\
\hline
\end{tabular}

Notes: The number of observations is 38,482 in all regressions. ${ }^{*}$ significant at $5 \%$; ${ }^{* *}$ significant at $1 \%$. Numbers in brackets are standard errors. 'sum of lags' is the sum of the contemporaneous and 4 lags of the coefficients (see text for more details). Numbers in braces are percent change in hospitalizations from $.01 \mathrm{ppm}$ increase in ozone. $\mathrm{X} 2$ is the test statistic from a Hausman test comparing estimates in the even column with the preceeding odd column. Columns 2, 4, and 6 include controls for avoidance behavior (contemporaneous and 4 lags of smog alerts and PSI). All regressions include day of week dummies, year-month dummies, SRA fixed effects, and contemporaneous and 4 lags of maximum \& minimum temperature, percipitation, humidity, sun cover, wind speed, carbon monoxide, and nitrogen dioxide. 
Table 6. Lag sensitivity of regression estimates of ozone on asthma hospitalizations by age

\begin{tabular}{|c|c|c|c|c|c|c|}
\hline & ${ }^{1} \mathrm{Ac}$ & 2 & ${ }^{3} \mathrm{Ag}$ & $64^{4}$ & 5 & 6 \\
\hline ozone (0 lags) & 0.177 & 0.176 & $0.536^{\star \star}$ & $0.433^{*}$ & $0.203^{*}$ & $0.307^{*}$ \\
\hline & [0.121] & [0.144] & [0.166] & [0.198] & [0.103] & [0.123] \\
\hline ozone (1 lag) & $0.308^{*}$ & $0.420^{*}$ & $0.870^{* *}$ & $0.843^{* *}$ & $0.266^{*}$ & $0.380^{*}$ \\
\hline & [0.142] & [0.177] & [0.195] & [0.243] & [0.121] & [0.151] \\
\hline ozone (2 lags) & $0.340^{*}$ & $0.625^{\star *}$ & $1.223^{* *}$ & $1.354^{* *}$ & $0.358^{* *}$ & $0.498^{* *}$ \\
\hline & [0.159] & [0.205] & [0.218] & [0.281] & {$[0.136]$} & [0.175] \\
\hline ozone (3 lags) & $0.468^{* *}$ & $0.976^{* *}$ & $1.237^{* *}$ & $1.325^{* *}$ & $0.419^{* *}$ & $0.518^{* *}$ \\
\hline & {$[0.173]$} & [0.228] & {$[0.237]$} & [0.313] & {$[0.148]$} & [0.194] \\
\hline ozone (4 lags) & $0.401^{*}$ & $1.061^{* *}$ & $1.356^{* *}$ & $1.532^{* *}$ & $0.558^{* *}$ & $0.776^{* *}$ \\
\hline & [0.185] & [0.245] & [0.254] & [0.335] & [0.158] & [0.208] \\
\hline ozone (5 lags) & $0.425^{*}$ & $1.255^{\star *}$ & $1.371^{* *}$ & $1.521^{* *}$ & $0.543^{* *}$ & $0.718^{\star *}$ \\
\hline & {$[0.196]$} & {$[0.262]$} & [0.270] & [0.360] & [0.168] & [0.224] \\
\hline ozone (6 lags) & $0.462^{*}$ & $1.411^{* *}$ & $1.203^{* *}$ & $1.235^{\star *}$ & $0.571^{* *}$ & $0.729^{* *}$ \\
\hline & [0.208] & {$[0.280]$} & {$[0.285]$} & [0.384] & {$[0.177]$} & [0.238] \\
\hline
\end{tabular}

See notes to Table 5. The specification in each column is comparable to the corresponding column in

Table 5. Each row contains results including the specified number of lags. 
Table 7. Specification checks of estimates of ozone and avoidance behavior on asthma hospitalizations by age

\begin{tabular}{|c|c|c|c|c|c|c|}
\hline Age: & $\begin{array}{c}1 \\
5-19 \\
\end{array}$ & $\begin{array}{c}2 \\
20-64 \\
\end{array}$ & $\begin{array}{c}3 \\
65+ \\
\end{array}$ & $\begin{array}{c}4 \\
5-19 \\
\end{array}$ & $\begin{array}{c}5 \\
20-64 \\
\end{array}$ & $\begin{array}{c}6 \\
65+ \\
\end{array}$ \\
\hline & \multicolumn{3}{|c|}{ A. No Weather } & \multicolumn{3}{|c|}{ B. No Co-Pollutants } \\
\hline \multirow[t]{3}{*}{ ozone (sum of lags) } & $1.116^{* *}$ & $1.524^{* *}$ & $0.742^{* *}$ & $1.298^{* *}$ & $1.582^{* *}$ & $0.780^{* *}$ \\
\hline & {$[0.237]$} & [0.325] & [0.202] & {$[0.240]$} & [0.329] & [0.204] \\
\hline & $\{3.03\}$ & $\{2.07\}$ & $\{2.55\}$ & $\{3.52\}$ & $\{2.15\}$ & $\{2.68\}$ \\
\hline \multirow[t]{2}{*}{ alerts (sum of lags) } & $-0.166^{* *}$ & -0.038 & -0.012 & $-0.180^{* *}$ & -0.045 & -0.014 \\
\hline & {$[0.057]$} & {$[0.078]$} & {$[0.048]$} & {$[0.057]$} & {$[0.078]$} & [0.049] \\
\hline \multirow[t]{2}{*}{ PSI (sum of lags) } & 0.013 & -0.021 & -0.038 & 0.023 & -0.012 & -0.035 \\
\hline & {$[0.030]$} & {$[0.041]$} & {$[0.025]$} & {$[0.030]$} & {$[0.042]$} & {$[0.026]$} \\
\hline $\mathrm{F}($ alerts, $\mathrm{PSI})=0$ & 5.76 & 0.63 & 2.24 & 6.03 & 0.51 & 1.96 \\
\hline \multirow[t]{2}{*}{ Prob $>$ F } & 0.00 & 0.53 & 0.11 & 0.00 & 0.60 & 0.14 \\
\hline & \multicolumn{3}{|c|}{ C. ER Admissions } & \multicolumn{3}{|c|}{ D. Future Ozone and Information } \\
\hline \multirow[t]{3}{*}{ ozone (sum of lags) } & $0.787^{* *}$ & $1.052^{* *}$ & $0.500^{* *}$ & $1.020^{* *}$ & $1.719^{* *}$ & $0.831^{* *}$ \\
\hline & {$[0.178]$} & {$[0.273]$} & {$[0.158]$} & {$[0.277]$} & [0.384] & {$[0.238]$} \\
\hline & $\{2.14\}$ & $\{1.43\}$ & $\{1.71\}$ & $\{2.77\}$ & $\{2.33\}$ & $\{2.85\}$ \\
\hline \multirow[t]{2}{*}{ alerts (sum of lags) } & -0.073 & -0.003 & 0.012 & -0.105 & -0.038 & -0.049 \\
\hline & {$[0.042]$} & {$[0.064]$} & {$[0.037]$} & {$[0.062]$} & {$[0.086]$} & {$[0.054]$} \\
\hline \multirow[t]{2}{*}{ PSI (sum of lags) } & -0.013 & -0.010 & -0.022 & -0.018 & -0.020 & -0.025 \\
\hline & {$[0.022]$} & {$[0.034]$} & {$[0.020]$} & {$[0.036]$} & [0.049] & {$[0.031]$} \\
\hline $\mathrm{F}($ alerts, $\mathrm{PSI})=0$ & 3.79 & 0.09 & 0.71 & 3.29 & 0.46 & 1.92 \\
\hline Prob $>$ F & 0.02 & 0.91 & 0.49 & 0.04 & 0.63 & 0.15 \\
\hline \multirow[t]{2}{*}{ future ozone (sum of lags) } & & & & 0.414 & -0.496 & -0.124 \\
\hline & & & & {$[0.276]$} & [0.383] & [0.238] \\
\hline \multirow[t]{2}{*}{ future alerts (sum of lags) } & & & & -0.003 & 0.054 & -0.018 \\
\hline & & & & {$[0.062]$} & {$[0.086]$} & [0.053] \\
\hline \multirow[t]{2}{*}{ future PSI (sum of lags) } & & & & -0.014 & -0.030 & 0.026 \\
\hline & & & & {$[0.035]$} & {$[0.049]$} & {$[0.030]$} \\
\hline$F($ future alerts, future $P S I)=0$ & & & & 0.15 & 0.24 & 0.39 \\
\hline Prob $>$ F & & & & 0.86 & 0.79 & 0.67 \\
\hline
\end{tabular}

See notes to Table 5. All specifications include controls for avoidance behavior (contemporaneous and 4 lags of smog alerts and PSI). 'No Weather' excludes weather as independent variables. 'No Co-Pollutants' excludes co-pollutants as independent variables. 'ER Admissions' limits the dependent variable to emergency room admissions. 'Future' include 5 leads of ozone, information, and their interaction, weather, and co-pollutants. 